\title{
Improvement of Jute Packages to Resist Insects during Storage of Bean Seeds
}

\author{
R. H. Morsy Azzam ${ }^{1}$, M. A. Sorour ${ }^{2 *}$ and A. S. Elmahrouky ${ }^{2}$
}

${ }^{1}$ Dyeing and finishing Department, Helwan University-Faculty of applied arts-Textile Printing, Egypt

${ }^{2}$ Department of Food Engineering and Packaging, Food Technology Research Institute, Agricultural Research center, Egypt

\begin{abstract}
The most important factor for obtaining good fiber is the strength of adhesion between fiber and polymer. Jute bags were treated with aqueous extracts from two insecticidal plants, Chenopodium ambrosioides and Lantana camara, to reduce damage to stored bean seeds by Acanthoscelides obtectus. The hydrophobic nature of jute bags makes it difficult to adhere to plants extract due to the presence of hydroxyl groups in various constituents of jute and treatment of jute bags with sodium hydroxide $(5 \%)$ alleviate such problem. Infested bean seeds were kept in small treated jute bags (infestation rate 1\%) and stored for six months in order to evaluate the protection efficiency of the fabric against damage to bean seeds. Alkali jute bags were treated with different concentrations of L.camara and $C$. ambrosiodes extract $(10,20,30,40 \%)$, The least percent of bean seed damaged $2.5 \%$ was recorded for alkali jute bags treated with $40 \%$ L.camara extract.
\end{abstract}

Keywords: Jute bags; Storage; Plant extract; Bag treatment; Agriculture crops; Seed damage

\section{Introduction}

Jute is a soft vegetable fiber from the plant can be spun into coarse strong yarns. It has (58-63\%) of cellulose, which is produced by jute stem. It is used extensively for fabrics in the packaging of agricultural and industrial commodities, which require sacks and wrapping. It is grown in hot moist climates and is prevalent in India and Pakistan, although China is now a large producer. Thus jute is the most friendly fiber starting from seed to fiber; it is $100 \%$ bio-degradable and recyclable [1].

Jute exhibit many advantageous properties for use as reinforcement materials for composites, they are low-density materials yielding considerably lightweight composites with highly specific properties. Natural fibers also offer significant cost advantages and benefits associated with their processing, relative to synthetic fibers. Furthermore, they are a highly renewable resource, which reduces the dependency on petroleum oil [2].

Mohanty et al. [3] prepared the jute fabrics by washing it with $2 \%$ detergent solution at $70^{\circ} \mathrm{C}$ for $1 \mathrm{~h}$, then washed with distilled water and finally dried in a vacuum oven at $70^{\circ} \mathrm{C}$. The detergent washed fabrics were dewaxed with a 1:2 mixture of alcohol and benzene for $72 \mathrm{~h}$ at $50^{\circ} \mathrm{C}$, followed by washing with distilled water and drying. The dewaxed/defatted fabrics were treated with $5 \% \mathrm{NaOH}$ solution for 30 min. at $30^{\circ} \mathrm{C}$, then washed overnight in running tap water and then with distilled water followed by oven drying to obtain alkali treated fabrics.

Plant fibre composites combine good mechanical properties with low specific mass. However, their high moisture absorption, poor wettability and insufficient adhesion between untreated fibre and polymer matrix lead to debonding at fibre-matrix interface [4]. To improve the properties of their composites, natural reinforcing fibres can be modified by physical and chemical methods [5-7]. Plant fibres must exhibit a compatible surface morphology for the development of a coherent interface with matrix polymers but because of the surface impurities, present in plant materials the development of a good fibrematrix interface is impaired $[8,9]$. In order to make use of the good physical and structural characteristics of the fibers they are treated with chemicals such as caustic soda to modify surface topography and the fine structure. Partial removal of lignin and hemicelluloses on the alkali treatment of cellulose fibres was reported by [10].

Burchids are a major threat to stored legume grains in west and central Africa, and infestations by the most prominent species (Ancanthescelides obtectus) on common beans are responsible for grain losses estimated at $20-60 \%,[11,12]$ Such losses are determined to resource -poor farmers since grain legumes constitute their major source of cheap and high quality dietary protein [13-15].

The main causes of loss in storage systems have been discussed by many authors [16-18]. Many of the agents of the loss are interrelated (e.g. under-drying or wetting leads to mold and mites, many mites and some insects feed on molds. Insects spread fungal spores, and insect activity leads to increased moisture content).

The loss agents generally fall into three classes: unavoidable (e.g. weather), human- induced (e.g., contamination, spillage, theft), and pest-induced (e.g., insects, mites, rodents).

More than species of insects can occur in stored grain products. Fortunately, cold weather is very effective in minimizing insect infestations. Worldwide, literally hundreds of species of insects and mites occur in stored grain. About, $5 \%$ of the world's grain is destroyed in store by insects and much more than this is partially spoiled. Many purchasers will not accept infested grain. Finally, mites and some insects can induce allergies and cause digestive upsets in farm animal,

*Corresponding author: M. A. Sorour, Dept. of Food Eng. and Packaging, Food Technology Research Institute, Agricultural Research center, Egypt, E-mail: manal. sorour@yahoo.com

Received October 10, 2011; Accepted November 17, 2011; Published November 19, 2011

Citation: Morsy Azzam RH, Sorour MA, Elmahrouky AS (2011) Improvement of Jute Packages to Resist Insects during Storage of Bean Seeds. J Textile Sci Engg 1:101. doi:10.4172/2165-8064.1000101

Copyright: () 2011 Morsy Azzam RH, et al. This is an open-access article distributed under the terms of the Creative Commons Attribution License, which permits unrestricted use, distribution, and reproduction in any medium, provided the original author and source are credited. 
[19]. Even though control of these insects in long-term storage can be achieved by synthetic insecticides [20]. The widespread protection practice at the farmer level in these regions remains that of mixing grains with locally available natural substances such as wood-ash, fresh or dried plant leaves (Chiranjeevi, 1991; Rajapakse and van Emden, 1997) which they consider less hazardous and of no cost.

To obtain the aqueous extract from L.camara and C. ambresidios plants, $10 \mathrm{~g}$ of leaves of the plant were washed thoroughly with tap water and ground using a mixer grinder to make a paste; this was then diluted with $100 \mathrm{ml}$ of water, filtered through muslin cloth, and used immediately upon preparation for bag treatment as a $10 \%$ aqueous extract (w/v). To obtain plant powders, leaves were dried in an oven at $40^{\circ} \mathrm{C}$ for 7 days, finely ground, then mixed with seeds at the rate of $4 \%$ $(w / w)[14,15]$.

The main essential oils in L. camara are, Caryophyllene (16.37\%), euealyptol (10.75\%), $\alpha$-humelene (8.22\%), and germaerene-D (7.41\%) were present in major amounts and eontributed 42.75 percent of the total (Dua et al. 2010) Figure 1.

The chemical constituent analysis of the leaf oil. The main compounds of the oil were identified as a-terpinen (37.6\%), cymol (p-cymen) (50.0\%), ascaridole (3.5\%) and carvacrol (3.3\%) [13] Figure 2.

Koona et al. $[14,15]$ stated that infested and uninfested bean grains were kept in small jute bags (infestation rate $1 \%$ and $2 \%$ ), then mixed with the powder from the stem bark of Scorodophloeus zenkeri at the 2, 4 and $6 \%$ doses $(\mathrm{w} / \mathrm{w})$ and stored for 6 months in order to evaluate the protectant effect of this plant substance against damage to grains by the bean beetle Acanthoscelides obtectus. There was a significant treatment effect, the percentage of grain damage increasing with the infestation level. There was a significant negative relationship between the level of grain damage and the treatment dose. The potential for using this tropical plant at the farmer level in long-term storage of bean grain is discussed.
Caryophyllene $\left(\mathrm{C}_{15} \mathrm{H}_{24}\right)$

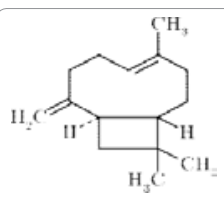

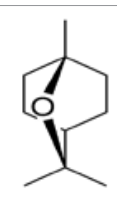

Euealyptol $\left(\mathrm{C}_{10} \mathrm{H}_{18} \mathrm{O}\right)$

uealyptol $\left(\mathrm{C}_{10} \mathrm{H}_{18} \mathrm{O}\right) \quad \alpha$-humelene $(\mathrm{C} 15 \mathrm{H} 24)$

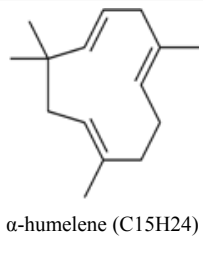

Figure 1: The main essential oil in L.camara extract.

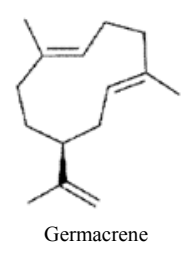

$\left(\mathrm{C}_{15} \mathrm{H}_{24}\right)$

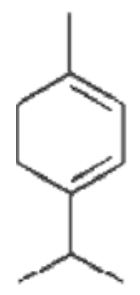

Terpinenes

(C10H16)

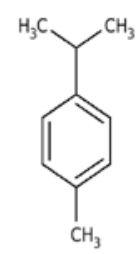

Cymene

(C10H14)

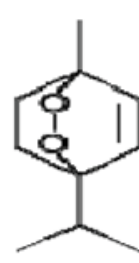

Ascaridole (C10H16O2)

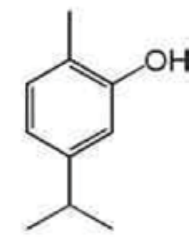

Carvacrol

(C10H14O)
Figure 2: The main essential oil in C. ambrosioides plant extract.
Koona and Koona [21] stated that jute bags impregnated with aqueous extracts from two insecticidal plants, Chenopodium ambrosioides and Lantana camara, were used to reduce damage to stored legume seeds by two major bruchid insect pests, Acanthoscelides obtectus and Callosobruchus maculatus, it was compared with a direct seed-treatment method using plant powders. In the first method bags were treated with a $10 \%$ concentration of the aqueous plant extract and filled with bean or cowpea seeds, whereas in the second method seeds were thoroughly mixed with leaf powder from the same plants at the rate of $4 \%(\mathrm{w} / \mathrm{w})$. The results show that bag-treatment method significantly reduced seed damage compared with the untreated control after 6 months of storage. The percent damage controlled by impregment bags method was significantly higher than the damage recorded in the seed-treatment method.

The objective of the present study is to treat jute bags with $\mathrm{NaOH}$ to improve interfacial adhesion of jute fiber, treat jute bags with the extract of Lantana camara and Chenopedium ambrosiodes to reduce the damage of bean seeds during storage.

\section{Experimental}

\section{Materials}

Jute packages were supplied by the public company of jute-Egypt. $L$. camara and C. ambrosiodes plants used in this research were collected from Faculty of Agricultural Cairo University in December.

\section{Jute packages treatment}

Jute bags were washed using $2 \%$ detergent solution at $70^{\circ} \mathrm{C}$ for $1 \mathrm{hr}$., then washed with distilled water and finally dried in a Laboratory oven at $70^{\circ} \mathrm{C}$. The defatted fabrics were treated with $\mathrm{NaOH}(5 \%)$ solution for $30 \mathrm{~min}$. at $30^{\circ} \mathrm{C}$ then washed thoroughly with distilled water to obtain alkali treated fabrics.

\section{Preparation of plant extract}

Leaves of L. camara and C. ambrosiodes were washed and dried naturally on laboratory benches at room temperature $\left(26-30^{\circ} \mathrm{C}\right)$ for 5 days until they were fully dried. Furthermore, four concentrations of each plant namely $10 \mathrm{gm}, 20 \mathrm{gm}, 30 \mathrm{gm}, 40 \mathrm{gm}$ of plant leaves were applied separately in $100 \mathrm{ml}$ boiling water for $10 \mathrm{~min}$. Preparation was made at concentration $(10,20,30,40 \mathrm{wt} / \mathrm{v} \%)$ and were filtered through a Whatman filter paper No.1 and stored at $\left(-20^{\circ} \mathrm{C}\right)$.

\section{Storage of bean seeds}

Clean healthy and uninfested bean seeds used for this study were obtained from the local market, its type was (Giza 3). Uninfected bean seeds had no holes and kept at $-18^{\circ} \mathrm{C}$ for two weeks to ensure that they were not infested, each treated jute bag was filled with 400 uninfested bean seeds to which 4 infested bean seeds were added making an infestation rate of $1 \%$, the bags were shaken thoroughly to ensure mixing of seeds. Bags were divided into groups according to different treatments. Jute bags were conducted in duplicate and average values reported. All bags were then placed on shelves in the laboratory $25^{\circ} \mathrm{C}$ in completely randomized design (Motoko, 1995). The storage period of seeds was 6 months; Data was collected every month on the number of damaged grains. A weevil perforation index (Koona et al., 2007) was calculated as: 
WPI

( \% treated seed perforated ) 100 ( $\%$ control seeds perforated $+\%$ treated seeds perforated )

A WPI $>50$ indicates a negative protectant effect, whereas a WPI $<50$ indicates a positive effect or a decrease in infestation.

\section{Results and Discussion}

\section{Damage by $A$. obtectus to bean seeds stored in treated jute} bags

The most important factor for obtaining good fiber is the strength of adhesion between fiber and polymer. Due to the presence of hydroxy and other polar groups in various constituents of jute, the moisture absorption is high, which leads to poor wettability and weak interfacial bonding between fibers and more hydrophobic matrices. Therefore, in order to develop composites with better mechanical properties, it is necessary to impart hydrphobicity to the fibers by suitable chemical treatments. Such surface modification of jute would not only decrease the moisture absorption, but would increase the wettability of fibers with polymer and the interfacial bond strength both critical value for obtaining better mechanical properties of the fiber [3].

- In the present work, we have investigated the effeThe percent of seed damaged stored in alkali treated jute bags $(5 \% \mathrm{NaOH})$.

- The percent of seed damaged stored in jute bags treated with different concentrations of L.camara extract.

- The percent of seed damaged stored in jute bags treated with then different concentrations of C. ambrosiodes extract.

- The percent of seed damaged stored in jute bags treated with $(5 \% \mathrm{NaOH})$ then different concentrations of L.camara extract.

- The percent of seed damaged stored in jute bags treated with $(5 \% \mathrm{NaOH})$ then different concentrations of C. ambrosiodes extract.

\section{Jute bags treated with plant extract}

Figures 3 and 4 that jute bags treated with different concentrations of Lantana camara extract $(10,20,30,40 \%)$ reduce the percent of seed damage from $4.24 \%$ to $2.5 \%$ as concentration of $L$. camara increased, while jute bags treated with different concentrations of C.ambrosioides extract decrease percent seed damaged decrease from 5.25 to $3 \%$, this may be due to that odors from both plants extract were capable of suffocating storage insects in jute bags. This mode of action would guarantee maximum grain protection even in larger containers such

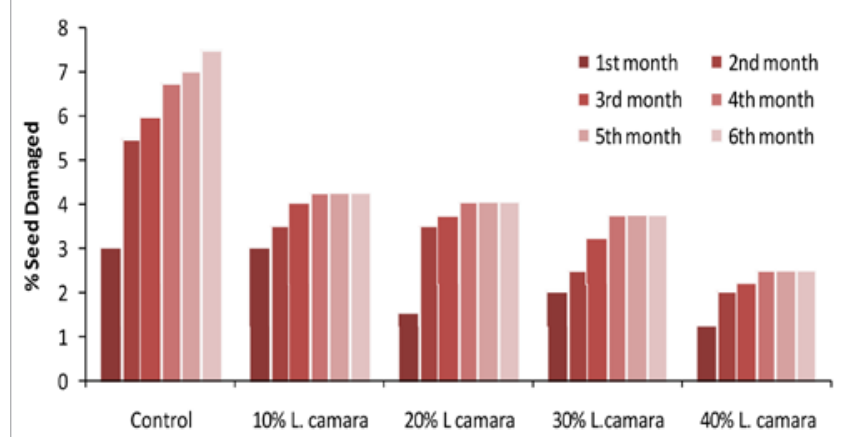

Figure 3: Damage of bean seeds stored in jute bags treated with different concentrations of $L$. camara extract $(10,20,30,40 \%)$.

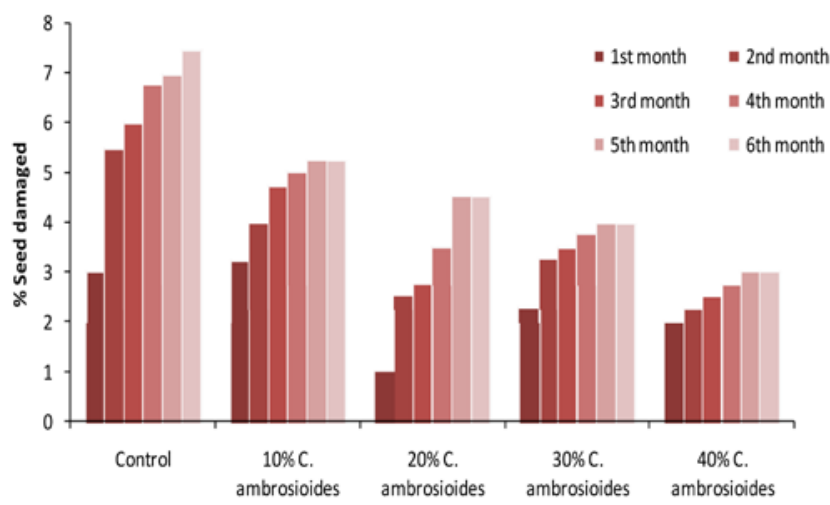

Figure 4: Damage of bean seeds stored in jute bags treated with different concentrations of C.ambrosioides extract (10, 20, 30, 40\%).

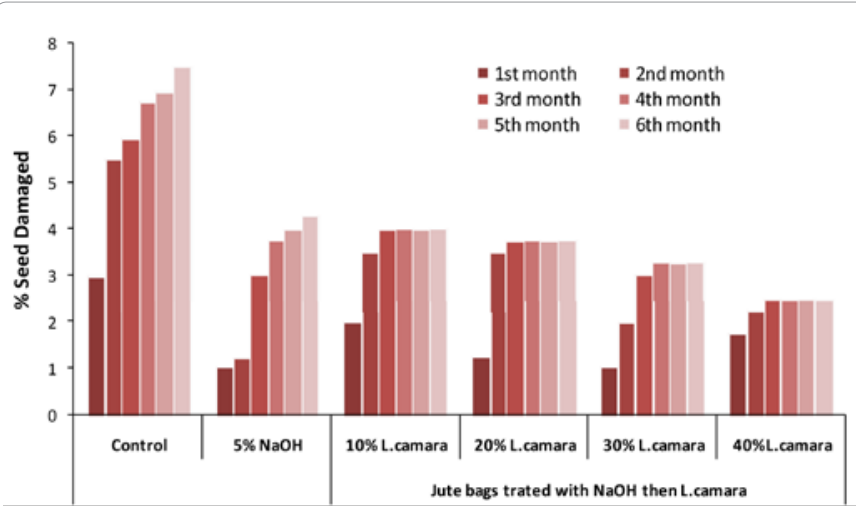

Figure 5: Damage of bean seeds stored in alkali treated jute bags $(5 \% \mathrm{NaOH})$ then treated with different concentrations of $L$.camara extract $(10,20,30,40 \%)$.

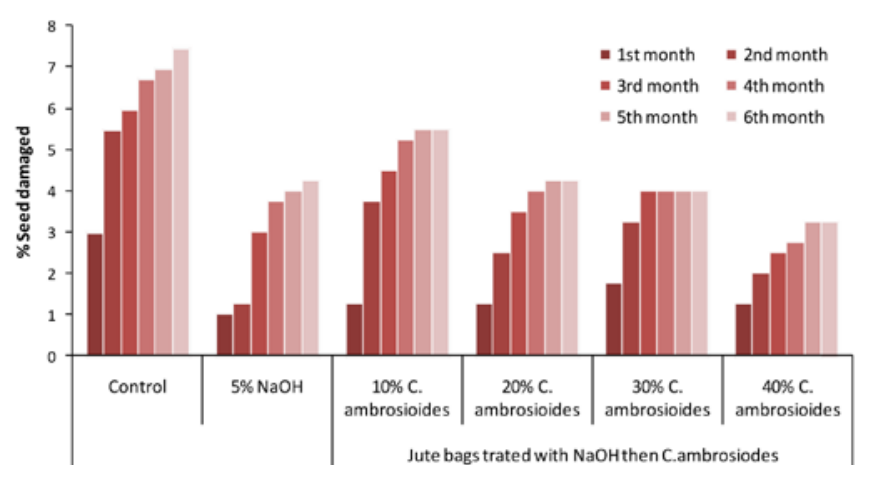

Figure 6: Damage of bean seeds stored in alkali treated jute bags $(5 \% \mathrm{NaOH})$ then treated with different concentrations of C.ambrosioides extract $(10,20$, $30,40 \%)$.

as the full-sized $50-100 \mathrm{~kg}$ bags commonly used for grain storage by farmers as previously discussed $[22,23]$.

\section{Jute bags treated with $\mathrm{NaOH}$ then plant extract}

Alkali treated bags $(5 \% \mathrm{NaOH})$ with different concentrations of L.camara extract $(10,20,30,40 \%)$ reduce the percent of seed damaged as shown in Figure 5. The results show that the highest percent of seed damaged was recorded on control bags (7.5\%), while the least percent was recorded on alkali treated bags with $40 \%$ L.camara extract $(2.5 \%)$ 
Citation: Morsy Azzam RH, Sorour MA, Elmahrouky AS (2011) Improvement of Jute Packages to Resist Insects during Storage of Bean Seeds. J Textile Sci Engg 1:101. doi:10.4172/2165-8064.1000101

Page 4 of 5

\begin{tabular}{|c|c|c|c|c|c|}
\hline Treated jute bags & Total No. of seeds & damaged seeds & Undamaged seeds & $\%$ seed damaged & WPI \\
\hline Control & 400 & 30 & 370 & 7.5 & \\
\hline $5 \% \mathrm{NaOH}$ & 400 & 17 & 383 & 4.25 & 36.17 \\
\hline 10\% L.Camara & 400 & 17 & 383 & 4.25 & 36.17 \\
\hline 20\% L.Camara & 400 & 16 & 384 & 4 & 34.78 \\
\hline 30\%L.Camara & 400 & 15 & 385 & 3.75 & 33.33 \\
\hline 40\%L.Camara & 400 & 10 & 390 & 2.5 & 25 \\
\hline \multicolumn{6}{|c|}{ Alkali treated jute bags $(5 \%)$ then different concentrations of L.Camara } \\
\hline $10 \%$ L.camara & 400 & 16 & 384 & 4 & 34.78 \\
\hline $20 \%$ L.camara & 400 & 15 & 385 & 3.75 & 33.33 \\
\hline $30 \%$ L.camara & 400 & 13 & 387 & 3.25 & 30.23 \\
\hline $40 \%$ L.camara & 400 & 10 & 390 & 2.5 & 25 \\
\hline \multicolumn{6}{|c|}{ Alkali treated jute bags $(5 \%)$ then different concentrations of $\mathrm{C}$. ambresidios } \\
\hline $10 \%$ C. ambresidios & 400 & 19 & 381 & 4.75 & 38.78 \\
\hline $20 \%$ C. ambresidios & 400 & 14 & 386 & 3.5 & 31.82 \\
\hline $30 \%$ C. ambresidios & 400 & 14 & 386 & 3.5 & 31.82 \\
\hline $40 \%$ C. ambresidios & 400 & 13 & 387 & 3.25 & 30.23 \\
\hline
\end{tabular}

Table 1: The weevil perforation index for bean seed damaged stored in treated jute bags.

as shown in Figure 5, this may be due to that alkali treatment improves the adhesive characteristics of fiber surface by removing natural and artificial impurities thereby producing a rough surface topography. The results confirmed that a stronger adhesion degree was obtained for composite jute strands probably due to the major number of hydrogen bonds between the components [3].

Figure 6 shows that the percent of seed damaged decrease as the concentration of C.ambrosioides extract increase. The highest percent of seed damaged was recorded on control bags (7.5\%); while the least percent was recorded on alkali treated bags $(5 \% \mathrm{NaOH})$ with $40 \%$ C.ambrosioides extract (3.25\%)

Table 1 shows the weevil perforation index (WPI) of all rates of treated bags indicated a positive effect ranging between 16 and 46 all being less than 50 . The least WPI was recorded 16 for jute bags treated with $5 \% \mathrm{NaOH}$ then $40 \%$ L.Camara extract. WPI was calculated according to equation (1).

\section{Conclusion}

Jute fibers are considered to be the most promising material because of its wide commercial availability in the required form and low cost. Jute bags treated with sodium hydroxide, $5 \%$ and plants extract (L.camara and C.ambrosioides). The results demonstrate that jute bags treated with sodium hydroxide and plant extract were able to reduce the percent of seed damaged of bean seeds during storage.

\section{References}

1. Pan N C, Day A, Kumar K Mahalanabis (1999) Chemical Composition of Jute and its Estimation. Man-made Textiles in India 9: 467 - 473

2. Khan F, Ahmed SR (1996) Chemical modification and spectroscopic analysis of jute fiber. Polymer Degradation and Stability 52: 335-340.

3. Mohanty AK, Khan MA, Hinrichsen G (2000) Influence of chemical surface modification on the properties of biodegradable jute fabrics-polyester amide composites. Composites Part A 31: 143-150.

4. Bengtsson M, Oksman K (2006) The use of silane technology in crosslinking polyethylene/wood flour composites. Composites Part A 37: 752 -765.

5. Sain M N, Kokta BV (1994) Polyolefin-wood filler composite. I. Performance of $m$-phenylene bismaleimide-modified wood fiber in polypropylene composite. $J$ Appl Polym Sci 54: 1545-1559.

6. Khan MA, Hassan MM (2006) Effect of $y$-aminopropyl trimethoxy silane on the performance of jute-polycarbonate composites.JAppl Polym Sci $100: 4142$ 4154.

7. Ichazo MN, Albano C, Gonzalez J, Perera R, Candal M V (2001) Polypropylene/ wood flour composites: treatments and properties. Compos Struct 54: 207-214.

8. Bledzki A K, Gassan J (1999) Prog Polym Sci 24 : 221

9. Gassan J, Mildner I, Bledzki AK (1999) Influence of fiber structure modification on the mechanical properties of flax fiber-epoxy composites. Compos Mater 35: $435-440$.

10. Sreekala MS, Kumaran MG, Thomas S (1997) Oil palm fibers: morphology, chemical composition, surface modification, and mechanical properties, J Appl Polym Sci 66: 821-835

11. Curtin-L SM (1965) Healing Herbs of the upper Rio Grande, Southwest Museum, Los Angeles

12. Gadano A, Gurni , Lo'pez P, Ferraro G,Carballo M (2002) In vitro genotoxic evaluation of the medicinal plant Chenopodium ambrosioides L.Journal of Ethnopharmacology 81: 11-16.

13. Tapondjou LA, Adler C, Bouda H, Fontem DA (2002) Efficacy of powder and essential oil from Chenopodium ambrosioides leaves as post-harvest grain protectants against six-stored product beetles. Journal of Stored Products Research 38: 395-402.

14. Koona P, Richard, Ghogomu, Koona S, Georges Ngando, et al. (2007) The Use of Powder from the Stem Bark of Scorodophloeus zenkeri Harms for the Prevention of Damage to Stored Beans by Acanthoscelides obtectus Say. (Coleoptera: Bruchidae). Journal of Applied Sciences Research 3: 329-332.

15. Koona P, Tatchago V, Dorothy M (2007) Impregnated bags for safer storage of legume grains in West and Central Africa. Journal of Stored Products Research 43: 248-251.

16. Ghelardini C, Galeotti N, Cesare Mannelli D, Mazzanti G, Bartolini A (2001) Local anaesthetic activity of beta-caryophyllene. Farmaco 56: 387-389.

17. Juergens UR, Dethlefsen U, Steinkamp G, Gillissen A, Repges R, et al. (2003) Anti-inflammatory activity of 1.8-cineol (eucalyptol) in bronchial asthma: a double-blind placebo-controlled trial. Respir Med 97: 250-256.

18. Glenn Tinseth ( 1993) Hop Aroma and Flavor. Brewing Techniques 4789.

19. Rivero-Cruz B, Rivero-Cruz I, Rodriguez JM, Cerda-Garcia-Rojas CM, Mata 
Citation: Morsy Azzam RH, Sorour MA, Elmahrouky AS (2011) Improvement of Jute Packages to Resist Insects during Storage of Bean Seeds. J Textile Sci Engg 1:101. doi:10.4172/2165-8064.1000101

Page 5 of 5

R (2006) Qualitative and quantitative analysis of the active components of the essential oil from Brickellia veronicaefolia by nuclear magnetic resonance spectroscopy. J Nat Prod 69: 1172-1176.

20. Champ BR, Dyte CE (1976) Report of the FAO Global Survey of Pesticide Susceptibility of Stored Grain Pests. FAO Plant Production and Protection Series No. 5. FAO, Rome.

21. Koona P, Koona E S O (2006) Protectant Effect of Erigeron Floribundus (Asteraceae) Against Damage to Stored Legume Seeds by Infesting Bruchids in the Western Highlands of Cameroon. Journal of Agriculture and Biological Sciences 2: 303-306.

22. Saxena RC, Dixit OP, Harshan V (1992) Insecticidal action of Lantana camara against Callosobruchus chinensis (Coleoptera: Bruchidae). Journal of Stored Products Research 28: 279-281.

23. Motoko FX (1995) Effects le poudre et des extraits de planets insecticides sur deux insects de stocks de denrees alimentaires. These de Doctorat de $3 \mathrm{e}$ cycle. CARFOP, Dschang, Cameroun, pp 139. 